\title{
Xylem embolism spread is largely prevented by interconduit pit membranes until the majority of conduits are gas-filled
}

\author{
Rodrigo Avila ${ }^{1}$, Xinyi Guan ${ }^{2}$, Cade Kane $^{3}$, Amanda Cardoso ${ }^{3}$, Timothy Batz ${ }^{3}$, Fabio \\ DaMatta $^{1}$, Steven Jansen ${ }^{4}$, and Scott McAdam ${ }^{5}$ \\ ${ }^{1}$ Universidade Federal de Viçosa \\ ${ }^{2}$ University of Ulm Institute for Systematic Botany and Ecology \\ ${ }^{3}$ Purdue University \\ ${ }^{4}$ Institute of Systematic Botany and Ecology \\ ${ }^{5}$ University of Tasmania
}

August 11, 2021

\begin{abstract}
Xylem embolism resistance varies across species influencing drought tolerance, yet little is known about the determinants of the embolism resistance of an individual conduit. Here we conducted an experiment using the optical vulnerability method to test whether individual conduits have a specific water potential threshold for embolism formation and whether pre-existing embolism in neighbouring conduits alters this threshold. Observations were made on a diverse sample of angiosperm and conifer species through a cycle of dehydration, rehydration and subsequent dehydration to death. Upon rehydration after the formation of embolism, no refilling was observed. When little pre-existing embolism was present, xylem conduits had a conserved, individual, embolism resistance threshold that varied across the population of conduits. The consequence of a variable conduit-specific embolism threshold is that a small degree of pre-existing embolism in the xylem results in an apparently more resistant xylem in a subsequent dehydration, particularly in angiosperms with vessels. While our results suggest that pit membranes separating xylem conduits are critical for maintaining a conserved individual embolism threshold for given conduit when little pre-exisiting embolism is present, as the percentage of embolized conduits increases, gas movement, local pressure differences, and connectivity between conduits increasingly contribute to embolism spread.
\end{abstract}

\section{Introduction}

Water is transported under negative pressure through a plant in a complex network of xylem cells (Dixon and Joly 1895). Being under negative pressure means the water column is at constant risk of interruption by large bubbles (Tyree and Sperry 1989). When tension increases, such as when soil water is limiting or when evaporative demand exceeds hydraulic conductivity, there is an increasing likelihood of embolism formation, which blocks the internal flow of water (Urli et al. 2013; Brodribb and Cochard 2009). The primary source of gas leading to embolism formation is believed to be air entrance through the nanoscale pores of pit membranes from neighbouring gas-filled conduits (Choat et al. 2015b; Tyree and Sperry 1989; Guan et al. 2021; Kaack et al. 2021). If water stress is not relieved, more xylem conduits will experience embolism, leading to progressive declines in hydraulic conductivity, and eventual failure of the hydraulic system, with consequences for photosynthetic performance and potential dieback of organs (Urli et al. 2013; Brodribb and Cochard 2009; Adams et al. 2017; Cardoso et al. 2020a).

A suite of adaptations have evolved to reduce the likelihood of embolism spread when hydrated xylem is exposed to negative pressure, with species native to seasonally dry environments having xylem that is highly resistant to embolism formation (Choat et al. 2012). These adaptations range from gross anatomical 
differences in xylem conduits, like reduced conduit diameter, length, interconnectivity, or increased cell-wall thickness (Hacke et al. 2001; Blackman et al. 2010; Jacobsen et al. 2019; Scoffoni et al. 2017b; Schumann et al. 2019), through to micro-anatomical variation such as increased pit membrane thickness (Li et al. 2016; Kaack et al. 2019), or in conifers, an increased torus overlap (Bouche et al. 2014). Considerable focus has been placed on establishing relationships between xylem anatomy and emergent traits that surmise embolism resistance, such as the water potential at which $50 \%$ of the xylem is embolised $\left(P_{50}\right)$ (Choat et al. 2018; Brodribb et al. 2020b). Less emphasis has been placed on understanding if individual xylem conduits have specific thresholds at which embolism will form (Jacobsen et al. 2019).

Assuming that most declines in xylem hydraulic conductance during drought are due to embolism then the gradual decline in hydraulic conductance as a drought progresses (Sergent et al. 2020), suggests that there might be a range of water potentials at which embolism events will occur across a population of xylem conduits. This range of water potential is typically quantified by the slope of vulnerability curves, with a narrow range and a steep slope characterising vulnerable species, and a wider range and flatter slope more embolism resistant species (Kaack et al. 2021). Methods that are capable of visualizing individual embolism events support the idea that individual embolism events will occur over a wide range of water potentials in many species in both stem and leaf xylem (Jacobsen et al. 2019; Venturas et al. 2016; Johnson et al. 2020; Knipfer et al. 2015). In stems the first embolism events are often observed near the primary xylem (Choat et al. 2015a), or in some cases the largest volume vessels (Jacobsen et al. 2019; Johnson et al. 2020; Knipfer et al. 2015), suggesting these conduits embolise first. In leaves, the first embolism events are almost always observed in the midrib and proceed, as leaf water potential declines, through the increasingly higher orders of veins (Skelton et al. 2017; Brodribb et al. 2016a; Scoffoni et al. 2017b).

The apparently wide range of water potentials at which embolism formation will occur could also be explained by a temporal aspect of embolism spread, because propagation is largely known to occur from an embolised to a non-embolised conduit, suggesting that pre-existing embolism or the availability of gas affects the actual spreading process (Guan et al. 2021; Wason et al. 2021). Once initial embolism has formed in xylem conduits, extrinsic factors beyond the anatomy of a single conduit, such as the proximity of water-filled conduits to embolised ones, cut-open conduits, and hydraulic segmentation can influence the likelihood of embolism formation (Choat et al. 2010; Knipfer et al. 2015; Choat et al. 2015b; Torres-Ruiz et al. 2016; Lamarque et al. 2018; Guan et al. 2021). Gas-filled conduits may act as a source of embolism propagation if a plant experiences a subsequent drought, thereby rendering neighbouring water-filled conduits more vulnerable. Pit membranes in the bordered pits between xylem conduits are believed to prevent this spread of air between conduits (Choat et al. 2008). In conifers with torus and margo pit membranes, aspiration of the torus prevents the spread of air from embolized tracheids into neighbouring sap-filled tracheids (Liese and Bauch 1967; Hacke et al. 2004; Pittermann et al. 2005). In angiosperms, the multiple pore constrictions in pit membranes with a given thickness fulfil a similar function, with the most narrow pore constriction determining mass flow of gas (Kaack et al. 2021).

The pattern of embolism events in leaves suggest that the proximity to air-filled neighbours influences the vulnerability of individual conduits (Guan et al. 2021). While often initiated in the midrib, embolism can display an unpredictable pattern of progression across the network of leaf veins, with large areas, comprised of many hundreds of xylem conduits, often observed embolizing simultaneously (Brodribb et al. 2016b). In detached leaves in which all of the xylem conduits in a petiole are embolized, the seeding of embolism throughout the leaf venation network is accelerated, occurring at higher water potentials than in an intact leaf on dehydration (Guan et al. 2021).

The relative importance of individual conduit traits versus the hydration status of surrounding conduits on determining the embolism resistance of an individual xylem conduit remains largely unknown. There is evidence suggesting gas-filled conduits make water filled neighbours more vulnerable (Knipfer et al. 2015; Choat et al. 2015b; Torres-Ruiz et al. 2016), yet pit membranes greatly reduce the spread of gas into water-filled conduits from embolized neighbours (Choat et al. 2008). To what extent does the presence of pre-existing embolism influence the vulnerability of the remaining xylem? Here we designed an experiment 
in which to test four hypotheses related to this question. The first hypothesis is that individual conduits have a specific water potential threshold at which an embolism will occur, and that pit membranes reduce the likelihood of embolism spread between gas and water-filled conduits under a narrow range of pressure differences. Challenges in testing this hypothesis are the lack of accurate water potential measurements at the individual conduit level (Bouda et al. 2019), and the uncoupling of pressure-driven embolism propagation from temporal effects. The second hypothesis is that pre-existing embolism changes the apparent embolism resistance of remaining individual water-filled conduits. If each conduit has a high fidelity to an individual threshold at which embolism will occur, then the most vulnerable conduits will consistently experience embolism earliest in drought, such that if drought is abated and refilling does not occur, then the relative embolism resistance of the remaining xylem may appear to be higher than the conduits with a low embolism resistance. Additionally, we hypothesize that on rehydration no refilling of embolized conduits will occur and that leaf xylem behaves in a similar way to stem xylem.

To test these hypotheses, we selected five angiosperm species with xylem consisting of vessels and one vesselless angiosperm species, all with uniform pit membranes, and three conifers with tracheid-based xylem separated by torus-margo pit membranes. Embolism was observed using the optical method, which is nondestructive, and permits a clear visualization of embolism events, through a cycle of dehydration to a variable degree of embolism, rehydration, and then subsequent dehydration to complete desiccation.

\section{Materials and methods}

The five vessel-bearing angiosperm species used in this study wereIlex verticillata (L.) A.Gray [Aquifoliaceae], Rhododendron hirsutum L. [Ericaceae], Ficus religiosa L. [Moraceae], Tilia cordata Mill. [Malvaceae] andLindera benzoin L. [Lauraceae], the vessel-less angiosperm was Drimys winteri J.R. Forst \& G.Forst. [Winteraceae], and three conifer species were Agathis robusta (C.Moore ex. F.Muell) Bailey [Araucariaceae], Tsuga canadensis (L.) Carrière [Pinaceae] and Torreya californica Torr. [Taxaceae]. Plants of Ti. cordata , and Ts. canadensis were grown outside in the grounds of the Botanical Gardens of Ulm University, Ulm (Germany) ( $\left.48^{\circ} 25^{\prime} \mathrm{N}, 9^{\circ} 57^{\prime} \mathrm{E}\right), F$. religiosa , A. robusta, and D. winteri in the glasshouses of the Botanical Gardens of Ulm University, I. verticillata, L. benzoin and To. californica were grown in the glasshouses of Purdue University, West Lafayette (Indiana, USA) (40 25' N, $86^{\circ} 54^{\prime} \mathrm{W}$, elevation: $\left.187 \mathrm{~m}\right) . R$. hirsutum

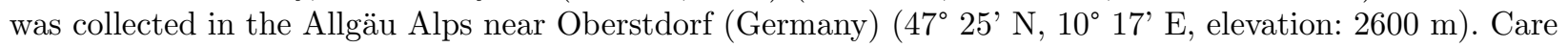
was taken to ensure no pre-existing embolism was present in the stems prior to experiments, with all plants grown under well-watered conditions for the duration of the growing season prior to harvesting. All stems were collected between May and June 2019 prior to dawn and were more hydrated than -0.4 MPa. Furthermore, air-filled xylem conduits appear as a blank area in the xylem when image processing is performed using the optical method. In all experiments no blank areas were detected in the observed areas of xylem at the completion of the experiment, providing support for no substantial, pre-existing embolism being present in any sample measured prior to the experiment.

Terminal branches ranging from 0.3 to $2.0 \mathrm{~m}$ long (all exceeding the length of the longest vessel determined by air injection for the five angiosperm species) were collected prior to dawn, cut under water, and bagged for approximately $1 \mathrm{~h}$, so that all experiments started with a stem water potential ( $\left.\Psi_{\text {stem }}\right)$ after equilibration of at least -0. $4 \mathrm{MPa}$. Stems were measured in all species, except L. benzoin in which experiments were conducted on leaves. Stems and leaves were fixed under a stereo microscope (SZMT2, optika, Italy) or in a Raspberry Pi clamp (opensourceOV.org). Vulnerability curves for stems were conducted on a region of the stem in which the bark was gently removed by hand, without touching the xylem beneath, and an adhesive gel (Tensive) immediately applied to the surface of the stem xylem to avoid dehydration and provide greater optics. A glass cover slip was placed on top of the adhesive gel to aid imaging. A stem psychrometer (ICT International, version 4.4) was then attached to the stem beyond the length of the longest vessel from the area imaged and $\Psi_{\text {stem }}$ measurements were collected every $10 \mathrm{~min}$. Branches were allowed to naturally dry while images were captured every 3 min.

All branches were rehydrated across a range of dehydrated $\Psi_{\text {stem }}$ to build a data set spanning a range of variation in the percentage of embolism at the point of rehydration across the species selected. At the 
point of rehydration, the end of the branch was excised under water (removing c. $1 \mathrm{~cm}$ from the cut end) until $\Psi_{\text {stem }}$ had fully recovered. Rehydration with water potentials approaching $0 \mathrm{MPa}$ generally occurred in less than 60 mins in all species. Branches were allowed to remain at a relaxed, high water potential for a variable amount of time ranging from 30 mins to $5 \mathrm{~h}$. The cut end of the stem was removed from water once rehydrated, and the branch was then allowed to bench dry a second time until all conduits had visibly embolized. Stem or leaf images were analysed using ImageJ (version $1.52 \mathrm{~h}, \mathrm{NIH}$, USA) to quantify the accumulation of embolized xylem area through time. Optical vulnerability curves were constructed as described by Brodribb et al. (2016b).

Based on the dehydration-rehydration-dehydration curves, we were able to determine the area of xylem that was embolised on the second cycle of dehydration at a more hydrated $\Psi$ than when rehydration occurred $(E$ pr) as follows:

$$
E_{\mathrm{pr}}=\left(\frac{E_{r 2}-E_{r 1}}{100-E_{r 1}}\right) \times 100
$$

Where $E_{r 1}$ is the percentage of accumulated embolized xylem area at the moment of rehydration and $E_{r 2}$ was the percentage of accumulated embolized xylem area that occurred prior to when plants reached the same $\Psi$ at which rehydration occurred.

Based on the dehydration-rehydration-dehydration curves, we also determined the $P_{50}$ (calculated by considering all events of embolism obtained using the dehydration-rehydration-dehydration curves), and an apparent $P_{50}\left(P_{50 \mathrm{r}}\right)$ that was obtained based only on the embolism events that occurred on the second cycle of dehydration. From these values we were able to calculate the percentage change in $P_{50}$ due to pre-existing embolism using the follow equation:Percent change in apparent $P_{50}=\left(\frac{P_{50}-P_{50 r}}{P_{50}}\right) X 100$

We conducted the experiment at least once in all species, three times inI. verticillata and $R$. hirsutum and twice in L. benzoin and F. religiosa. For To. californica, three rehydration curves were performed at the same $E_{r 1}$ and the results are presented as a mean of these three experiments (Supplementary Figure S1).

\section{Results}

Using the optical method, we were able to observe clear embolism events in xylem during dehydration. In most of the species observed these embolism events began once plants were dehydrated to at least -1 $\mathrm{MPa}$ and accumulated as $\Psi$ declined (Figure 1). When rehydrated, $\Psi$ recovered within 60 minutes to high values similar to those observed in the hydrated stems at the start of the experiment. However, differences were observed in the cessation of embolism formation upon rehydration across the species observed. In the angiosperm I. verticillatarehydrated just after $50 \%$ of the xylem had embolized, very little $(1.7 \%$, Figure 1A) embolism was observed immediately after rehydration. Yet in the conifer A. robusta, also rehydrated just after $50 \%$ of the xylem had embolized, considerable embolism (10.3\%, Figure 1B) occurred as $\Psi$ was relaxing (Figure 1B). In no sample did we observe refilling of embolized conduits after stem rehydration. 

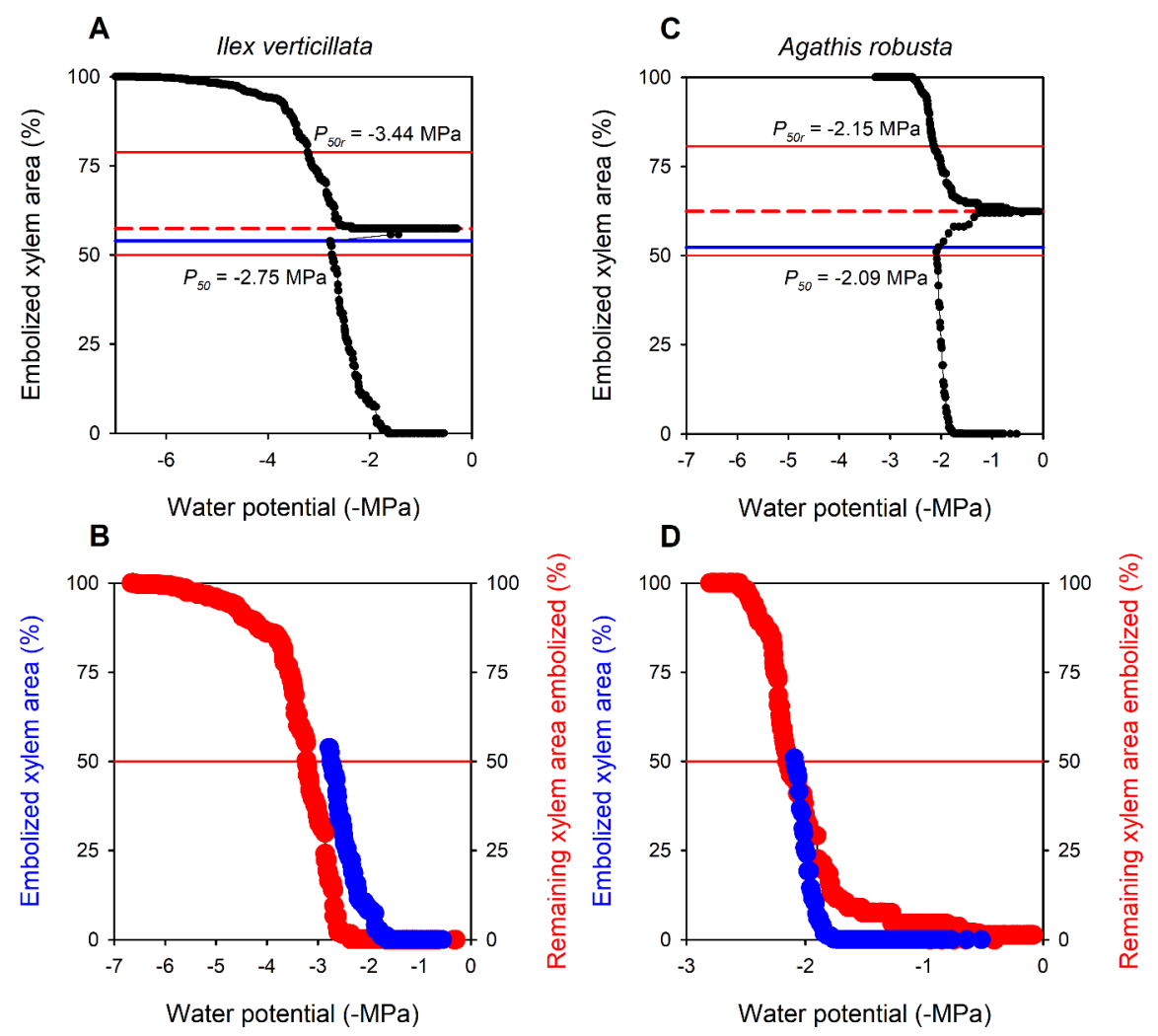

Figure 1. The relationship between cumulative embolised xylem area in stems and stem water potential $\left(\Psi_{\text {stem }}\right)$ during a cycle of dehydration, rehydration and dehydration in the angiospermIlex verticillata (A and B) and the gymnosperm Agathis robusta (C and D), with vessel and tracheid-based xylem, respectively. In $\mathrm{A}$ and $\mathrm{C}$ the solid red lines indicate $\Psi_{\text {stem }}$ at which $50 \%$ of the xylem area was embolized $\left(P_{50}\right)$ on the initial dehydration, and the $\Psi_{\text {stem }}$ at which $50 \%$ of the remaining stem xylem area was embolized $\left(P_{50 \mathrm{r}}\right)$ on the second dehydration. The dashed red line represents the beginning of second period of dehydration. The solid blue line represents the embolized area when rehydration occurred. In B and D cumulative embolized xylem area as a percentage of total embolized area (blue) on the first cycle of dehydration is shown alongside the cumulative embolized xylem area as a percentage of remaining un-embolized xylem area on the second cycle of dehydration (red). Horizontal red lines indicate when $50 \%$ of the total or remaining xylem area was embolized. Temporal traces of water potential and embolism accumulation through time can be found in Supplementary Figures S1A and S1B.

On the second period of dehydration, embolism occurred in the remaining conduits that had not embolised prior to rehydration. Differences were observed in the $\Psi$ at which these embolism events first formed on the second dehydration that influenced the apparent embolism resistance of the remaining water-filled xylem conduits (Supplementary Figure S1). In most species embolism events on the second dehydration often did not form until $\Psi$ had declined to values similar to those measured when the stem was rehydrated (Figure 1B; Supplementary Figure S2). In I. verticillata the impact of a lack of embolism formation at relatively high $\Psi$ compared to when the first conduits embolized when initially dehydrated, meant that apparent $P_{50}\left(P_{50 r}\right.$ ) was $0.69 \mathrm{MPa}$ lower in the stem with $50 \%$ of xylem embolized, than $P_{50}$ in the stem when no xylem was embolized (Figure 1A and B). In contrast in the conifer species assessed, embolism was often observed to form at the $\Psi$ at which embolism initially started to occur on the first dehydration (Figure 1C and D; Supplementary Figure S1). In $A$. robusta this resulted in an apparent $P_{50 r}$ that was only $0.06 \mathrm{MPa}$ lower in the stem with $50 \%$ of xylem embolized, than $P_{50}$ in the stem with no pre-exisiting embolism (Figure $1 \mathrm{C}$ and D). 
Differences between species in the nature of xylem embolism formation during rehydration and on the second cycle of dehydration were also apparent when cumulative embolism observations were plotted against time (Figure 2). In a representative trace from a stem of the angiosperm species Rhododendron hirsutum with vessel-based xylem, embolism first started to occur once $\Psi$ reached $-1.0 \mathrm{MPa}$, and progressively continued until $-1.54 \mathrm{MPa}$, when approximately $50 \%$ of the total xylem area was embolized (Figure 2A). After rehydration, which occurred at $-1.54 \mathrm{MPa}$, there was a complete and fast cessation of embolism accumulation (Figure 2A). During the second cycle of dehydration, new embolism events were only observed to form in the xylem after $\Psi$ had declined to $-1.54 \mathrm{MPa}$, which occurred $10 \mathrm{~h}$ after rehydration (Figure $2 \mathrm{~A}$ ). There was a similar slope in the decline of water potential through time on the first and second dehydration, however, once embolism began to form on the second dehydration the slope of water potential decline over time declined. 


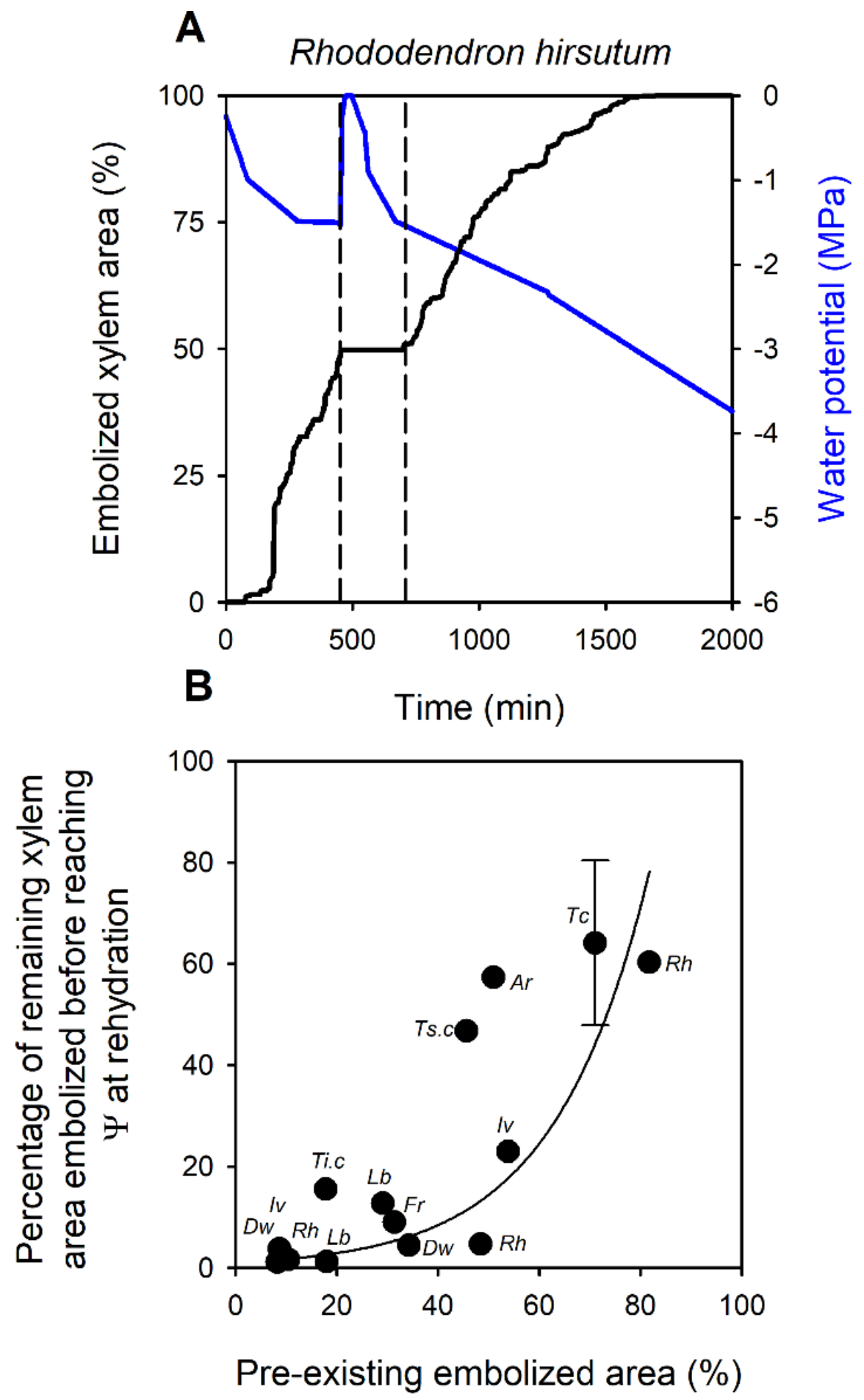

Figure 2. (A, B) Representative trace of the percentage of embolized xylem area (blue) and stem water potential $\left(\Psi_{\text {stem }}\right)$ (black) plotted against time in a branch of the angiosperm Rhododendron hirsutum. The vertical dashed lines indicate the period between rehydration and the point at which the $\Psi_{\text {stem }}$ on the second dehydration had declined to the $\Psi_{\text {stem }}$ when the branch was first rehydrated. (B) The relationship between the area (\%) of pre-existing embolism at rehydration and the relative area (\%) of xylem embolised on the 
second cycle of dehydration occurring at a more hydrated $\Psi$ than when the branch was rehydrated. An exponential relationship is plotted $\left(\mathrm{P}<0.0001, \mathrm{R}^{2}=0.69\right)$. A mean $(\mathrm{n}=3, \pm \mathrm{SE})$ is shown for T. californica . All traces used to assemble this dataset are included in Supplementary Figure S1. Species abbreviations are Tc T. californica ; Ar Agathis robusta ;Ts.c Tsuga canadensis ; Dw Drimys winteri ; Rh R. hirsutum ; Iv Ilex verticillata ; Fr Ficus religiosa ; Ti.c Tilia cordata ; Lb Lindera benzoin.

When branches, regardless of whether they had xylem comprised of vessels or only tracheids, were rehydrated at a $\Psi$ more hydrated than $P_{50}$, there were very few if any embolism events observed on the second cycle of dehydration at a $\Psi$ more hydrated than when the stem was rehydrated (Figure 2B; Supplementary Figure S2). Once xylem had experienced around $60 \%$ of area embolized then an increasing percentage of the remaining xylem on the second cycle of dehydration was observed to embolize at a $\Psi$ that was more hydrated than when the stem was rehydrated (Figure 2B; Figure 3). In three individual stems of $R$. hirsutum that were rehydrated at different percentages of embolized xylem area we found on the second cycle of dehydration that there was little or no embolism formation ( $1.5 \%$ or $0 \%$ of total xylem area) prior to stem dehydration to the $\Psi$ at which rehydration occurred when either $10.4 \%$ or $49.5 \%$ of total xylem area was embolized, respectively (Figure 3 ). This contrasts with a branch that was rehydrated when $81.7 \%$ of xylem area had embolized, in this branch on the second cycle of dehydration embolism began to form at $-0.56 \mathrm{MPa}$ (initial embolism events on the first dehydration occurred at a mean $\Psi$ of $-0.96 \pm 0.05$ (SE) MPa) and continued to accumulate linearly with declining $\Psi$ (with a slope of $3.7 \%$ remaining embolized xylem area bar $^{-1}$ ) such that when the stem had reached the $\Psi$ at which rehydration occurred more than $56 \%$ of the remaining xylem area had embolized (equivalent to $10 \%$ of the total xylem area of the stem) (Figure 3). 

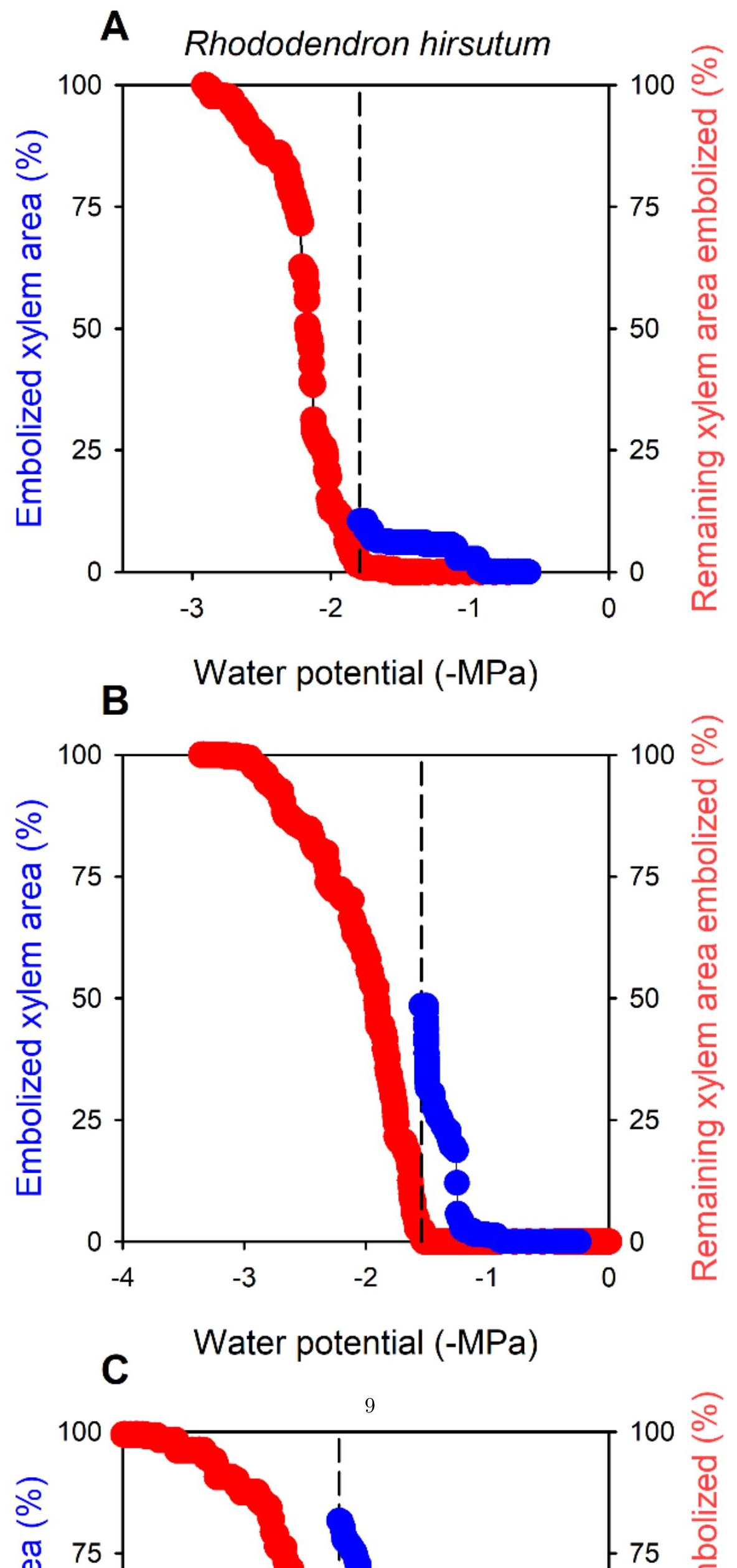
Figure 3. Cumulative embolized xylem area as a percentage of total embolized area on the first cycle of dehydration (blue) in three stems of Rhododendron hirsutum that were rehydrated at varying degrees of embolized xylem area. The water potential at rehydration is marked by a vertical dashed line. Cumulative embolized xylem area as a percentage of the remaining un-embolized xylem area on the second cycle of dehydration (red) is also shown. Temporal traces of water potential and embolism accumulation through time can be found in Figure 2, Supplementary Figure S1F and S1G. Similar traces for all other species are found in Supplementary Figure S2.

Differences across species in the $\Psi$ that triggered embolism during a second cycle of dehydration had a considerable impact on whether pre-existing embolism in the xylem altered apparent $P_{50}$. In many cases, pre-existing embolism caused a minor increase in apparent embolism resistance, resulting in more negative values of apparent $P_{50}\left(P_{50 \mathrm{r}}\right)$, which was $P_{50}$ calculated from data collected only from embolism events that occurred on the second cycle of dehydration (Figure 4). We did note that in angiosperms the higher the percentage of pre-existing embolism in the xylem, the higher the percent change in apparent $P_{50}$, with $P_{50 \mathrm{r}}$ particularly differing from $P_{50}$ changing once $40 \%$ of xylem was embolized (Figure 4 ). In conifers, the degree of pre-existing embolism did not appear to alter apparent $P_{50}$ as much as in angiosperm species (Figure 4). In some conifer stems, with pre-existing embolism, apparent $P_{50}$ was slightly more negative, while in others apparent $P_{50}$ was less negative or even unchanged, irrespective of the degree of pre-existing embolism in the xylem (Supplementary Figure S1).

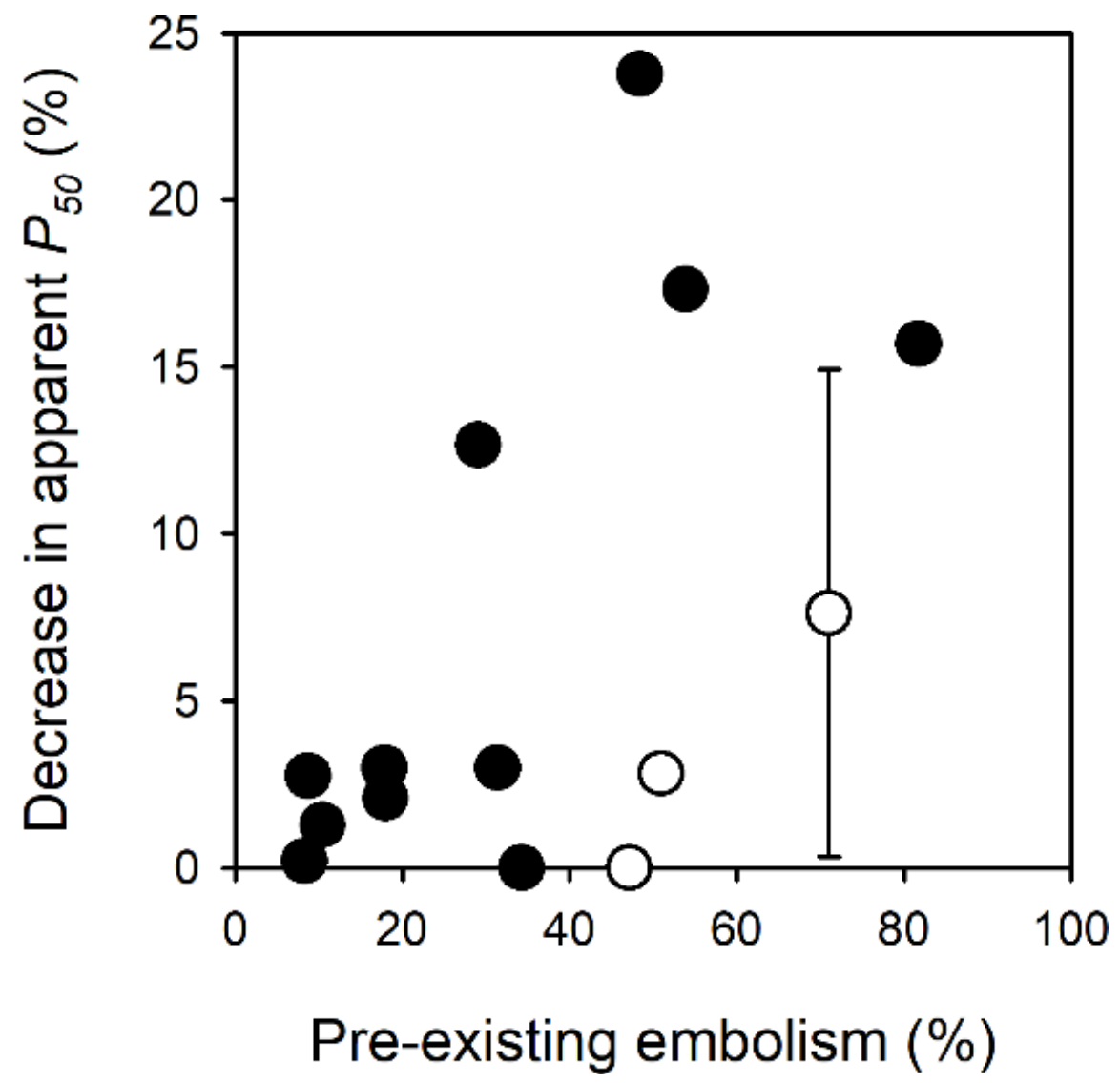

Figure 4. The impact of pre-existing embolized xylem area (\%) on the percent decrease in apparent $P_{50}$ of un-embolized xylem in angiosperms (black) and conifers (white). The conifer dataset includes a mean (n $=3, \pm \mathrm{SE}$ ) for $T$. californica . 
Rehydration of a $L$. benzoin leaf halted the spread of embolism formation when only $20 \%$ of the xylem was embolized (Figure 5A). This small percentage of embolism was concentrated in the midrib and major veins (Figure 5B). In this leaf no embolism was observed on the second dehydration until $\Psi$ had declined to the value it was when rehydration occurred. In a leaf of the same species in which $35 \%$ of the xylem area was embolized, rehydration was only able to reduce the rate of embolism accumulation (Figure 5C). In this leaf $9 \%$ of the xylem experienced embolism after rehydration and before $\Psi$ had declined to the value it was when rehydration occurred; after reaching this $\Psi$ the rate of embolism formation increased (Figure 5C). Leaves of $L$. benzoin could not be rehydrated once more than $50 \%$ of the xylem area embolized. 

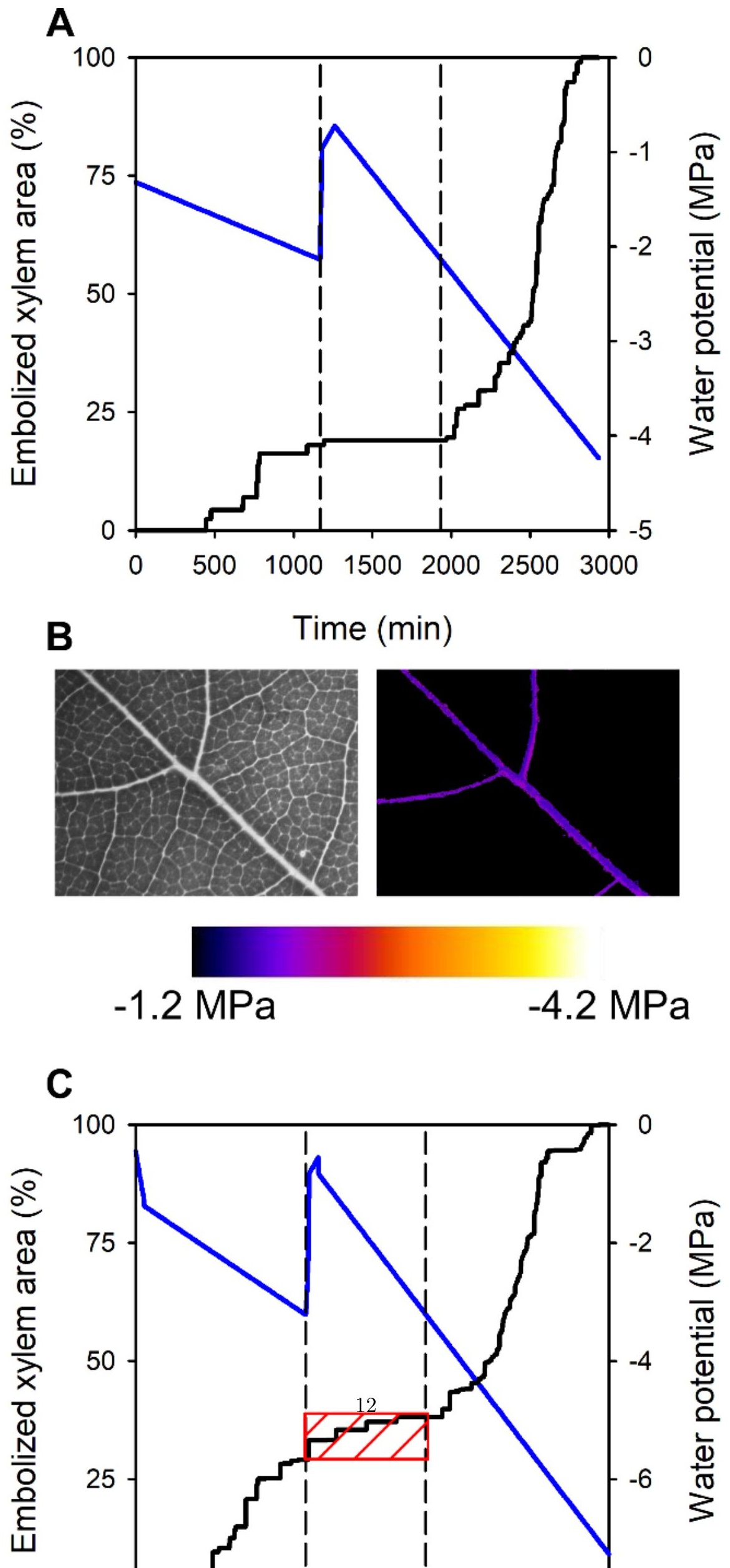
Figure 5. The percentage of embolized xylem area (black) and water potential (blue) plotted against time for a leaf of Lindera benzoin rehydrated at $20 \%$ embolized xylem area (A), in which only midrib and a few major veins had experienced embolism (B) and a leaf of the same species that was rehydrated when $35 \%$ of the xylem was embolized $(\mathrm{C})$. The vertical dashed lines in $\mathrm{A}$ and $\mathrm{C}$ indicate the period between rehydration and the point at which the $\Psi$ on the second dehydration had declined to the $\Psi$ when the branch was first rehydrated. The red box in $\mathrm{C}$ surrounds the percentage of embolized xylem area that occurred prior to $\Psi$ declining to the value recorded when the branch was rehydrated. In B the area of leaf imaged is shown on the left and the embolism events observed when rehydrated shown on the right, the scale bar depicts the $\Psi$ at which each embolism event occurred.

\section{Discussion}

The dehydration-rehydration-dehydration experiments conducted here indicate that embolism spreading is not random. While the water potentials of individual conduits remain impossible to determine, our experimental data suggests that pit membranes between adjacent conduits appear to work as fairly efficient safety valves when dehydration levels are rather low, ensuring that individual conduits have a high fidelity to a specific water potential threshold at which gas will invade the conduit. However, once sufficient embolism has accumulated in the xylem the spreading of embolism into water filled conduits does not appear to be strictly driven by a fixed pressure threshold between neighbouring conduits. When more than $60 \%$ of the xylem is embolized, gas spreads rapidly into water-filled conduits upon dehydration. This could be due to the amount of embolised conduits present, but also gas movement across embolised or sap-filled conduit lumina, pit membranes, and cell walls triggering embolism. These results have important implications for understanding the nature of embolism formation during dehydration as well as the impact of pre-existing embolism on the determination of relative embolism resistance.

\section{In the absence of considerable embolism individual conduits have specific thresholds for embolism resistance}

Our data suggest that in the absence of considerable embolism in neighbouring xylem conduits, individual conduits have a relatively unique, and highly conserved threshold $\Psi$ at which embolism will occur. This threshold, however, is not sustained when there is a high proportion of embolized conduits in the xylem (more than $60 \%$ ), an observation which supports the gas availability hypothesis proposed by Guan et al. (2021). We suggest that early during a drought, pit membranes provide a sufficient barrier to prevent embolism spread from gas-filled to neighbouring water-filled conduits, yet once more than $60 \%$ of conduits are gasfilled, diffusion of gas into water-filled conduits can be facilitated and occurs at relatively minor pressure differences across conduits.

Observations of variation in embolism resistance across xylem conduits have been reported by microCT imaging (Knipfer et al. 2015; Choat et al. 2015b; Torres-Ruiz et al. 2016; Jacobsen et al. 2019). A number of key anatomical traits vary across populations of xylem conduits that are associated with embolism resistance, including $(t / b)^{3}$ and vessel diameter, although we have no mechanistic explanation of how these traits affect embolism spreading (Hacke et al. 2001; Blackman et al. 2010; Jacobsen et al. 2019; Scoffoni et al. 2017b). In addition to anatomical differences that might set this variation in inter-conduit embolism resistance, variation across age class of xylem might also account for some of the spread in embolism resistance thresholds between conduits, with older xylem in Vitisbeing more vulnerable to embolism formation during drought (Brodersen et al. 2013), or more resistant within a single growing season (Sorek et al. 2021).

In angiosperms, pore constrictions in multi-layered pit membranes and/or a relatively high degree of isolation within the hydraulic conduit network provides added protection from the spreading of pre-existing embolism into water-filled conduits during drought (Johnson et al. 2020; Schenk et al. 2008; Avila et al. 2021). The narrow size of pore constrictions $(<50 \mathrm{~nm})$ and the highly variable pore size dimensions do not allow mass flow of gas from an embolised to a water-filled conduit under negative pressure (Yang et al. 2020; Kaack et al. 2019; Kaack et al. 2021). Surfactants coating the cellulose of pit membranes are believed to promote gas entry from a neighbouring embolised vessel into a water-filled conduit, but at the same time mitigate embolism spreading (Schenk et al. 2021). In addition to providing a physical barrier for the spreading of gas 
between an embolized and water-filled conduit, pit membranes may provide a short-term buffer to the further spreading of embolism, particularly when there are small numbers of embolized conduits. Upon embolism formation the water vapour in a conduit is at a negative pressure, and modelling suggests that it may take between $20 \mathrm{~min}$ and $10 \mathrm{~h}$ for this negative gas pressure to equilibrate with atmospheric pressure, during which time the embolized conduit can draw gas slowly across cell walls and rapidly across pit membranes from neighbouring gas filled, but also water-filled conduits, potentially buffering water-filled conduits from embolism (Wang et al 2015). Our experiments provide evidence that pit membranes can act as safety valves to delay the spread of embolism between neighbouring gas- and water-filled conduits.

Upon rehydration we did not observe conduit refilling (refilling of conduits have been observed using the optical method in the hydroids of a moss (Brodribb et al. 2020a)). Refilling of xylem on excised stem rehydration has been reported to occur (Trifilò et al. 2014), although the validity of these observations has been challenged (Lamarque et al. 2018). We did however observe a small degree of embolism formation persisting in a few species after rehydration (Figure 1B). This lag time in embolism cessation may be due to a slower, heterogenous reduction in the pressure difference between conduits in the area of xylem that we were observing with the optical method (Bouda et al. 2019), a phenomenon exacerbated by the presence of widespread embolism and associated decline in hydraulic conductivity. Furthermore, there may be a temporal component to embolism resistance, such that the longer a conduit experiences a negative $\Psi$ the more likely the chance of changes in water vapour and gas concentration in embolised conduits, or gas dissolved in xylem sap, which may trigger embolism spread (Guan et al. 2021, Kaack et al. 2021).

While embolism formation on rehydration was observed in all species, there appeared to be a tendency for more embolism formation after rehydration in conifer species (Supplementary Figure S1). To test whether pit membrane anatomy or conduit anatomy might explain why in some conifer species there was an exacerbated embolism spreading after rehydration we included the angiosperm species $D$. winteri in our sampling, a vesselless species with homogeneous pit membranes, as opposed to torus-margo pit membranes (Zhang et al. 2020). Unlike some conifers, the formation of embolism after rehydration in D. winteri was limited (Supplementary Figure S1C), suggesting that even though this species has only tracheids, an altered conformation caused by embolism is able to create a highly gas impermeable structure that protects the neighbouring conduits from air invasion (Zhang et al. 2020).

Other factors might also provide an explanation for the greater absence of embolism occurrence in angiosperm xylem after rehydration and on a second cycle of dehydration until reaching the $\Psi$ at which the branch was rehydrated, including the increased separation of conduits imbedded in a matrix of non-conductive xylem tissue, such as fibres and parenchyma that might offer a physical barrier for rapid air propagation through the xylem (Johnson et al. 2020; Avila et al. 2021), particularly compared to the tracheid based xylem of conifers, which is largely homogeneous and comprised of closely packed tracheids. The close proximity of tracheids with tracheid tips slightly bent and overlapping multiple neighbouring tracheids may facilitate a more rapid spread of embolism on a second dehydration cycle in conifers (Torres-Ruiz et al. 2016; Choat et al. 2015b), while the 3D reconstruction of vessel networks deserves more attention for angiosperms (Wason et al. 2021).

\section{Effect of pre-existing embolism on embolism resistance in leaves}

In the leaves of $L$. benzoin, in which only $20 \%$ of embolism was observed, mostly in the mid-rib, rehydration ceased the spread of embolism, and on a second period of dehydration, embolism only formed once $\Psi$ had declined to the values just prior to rehydration. In contrast in a leaf rehydrated when $35 \%$ of the xylem had embolized, rehydration was much less effective at reducing the spread of embolism on a second round of dehydration. These results suggest that the xylem of angiosperm leaves may be more susceptible to air invasion from embolism in neighbouring conduits or intercellular air spaces, than stems, although more work is required to address this possibility (Guan et al. 2021).

Effect of pre-existing embolism on stem vulnerability

By tracking embolism formation through a cycle of dehydration followed by rehydration, and subsequent 
dehydration to complete desiccation we show that the presence of pre-existing embolism in the xylem can lower an apparent optical $P_{50}$. Given that the presence of embolism in conduits is the most likely source of air seeding for future embolism events should $\Psi$ decline (Knipfer et al. 2015; Choat et al. 2015b; Torres-Ruiz et al. 2016), we suspected that the presence of pre-existing embolism would make xylem more vulnerable. Across our diverse sample of species, the more embolism initially present in the xylem, up to $60 \%$ embolism by area, the more negative the apparent $P_{50}$ of the remaining conduits became (Figure 4). Nevertheless, a temporal effect on embolism spreading can also be interpreted to contribute to the more negative $P_{50 \mathrm{r}}$ values, as the slope of vulnerability curves may illustrate the relative speed of embolism propagation, rather than absolute embolism resistance per se. Hence, it would be interesting to compare normal vulnerability curves with curves subject to multiple cycles of rehydration and dehydration, which is likely to occur to plants in the field.

The impact of pre-existing embolism on the reliability of vulnerability curves is a widely discussed topic (Martin-StPaul et al. 2014). So much so that flushing stems to remove embolism prior to measurements of hydraulic conductivity on centrifuge rotors is common practice. One explanation given for this practice is to counter the chance that pre-existing embolism spreads rapidly through the conduits resulting in artefacts of highly vulnerable $P_{50}$ values in a stem (Cochard et al. 2013; Hacke et al. 2015). Our results suggest that the presence of pre-existing embolism will occur in the most vulnerable conduits first, thus $P_{50}$ values, determined optically on xylem in which some conduits are already embolized, may appear more resistant to embolism formation than if measurements were conducted on xylem in which all of the conduits were water-filled. This mirrors the results of a report of a comparison of vulnerability curves measured using a centrifuge in short stem segments of long-vessel species that had and had not been flushed (Hacke et al. 2015). While we found that pre-existing embolism altered apparent $P_{50}$ in some species, the impact on apparent $P_{50}$ was generally a reduction of no more than $20 \%$. In this study we never measured an $R$-shaped curve using the optical method, despite initiating all experiments at high water potentials.

Besides accurate water potential measurements at the individual conduit level, a key unknown in our study is whether the differences in apparent embolism resistance driven by pre-existing embolism, translate to similarities in hydraulic vulnerability or drought tolerance. Given the strong correlations between mean embolism resistance of xylem between optical, microCT, pneumatic and hydraulic methods, when each is performed carefully (Sergent et al. 2020; Gauthey et al. 2020; Pereira et al. 2021), we hypothesize that there would be strong congruence with hydraulic vulnerability. However, given the considerable declines in hydraulic conductivity that would occur when a substantial percentage of xylem is embolized (Brodribb and Cochard 2009), the effect of this reduction, without reduced canopy transpiration, would accelerate declines in $\Psi$ during drought, and may not enhance survival.

\section{Conclusion}

Our experiments suggest that in the absence of considerable embolism in the xylem individual conduits have a specific $\Psi$ threshold at which embolism will form. However, as embolism accumulates in the xylem the likelihood of gas spreading from embolized to neighbouring water-filled conduits increases, leading to a rapid spreading of embolism on dehydration. We believe this is due to pit membrane anatomy, combined with the increased anatomical heterogeneity of angiosperm xylem, which provides both scope for variation in embolism resistance as well as a physical protection from gas movement from embolised conduits to sap-filled ones when there is not considerable gas presence in the xylem. Our results have important implications for understanding the impact of pre-existing embolism on the accurate determination of xylem vulnerability, with pre-existing embolism apparently increasing xylem embolism resistance. The impact of this effect of pre-existing embolism on drought survival through repeated drought events remains to be tested.

\section{Acknowledgements}

SAMM is grateful to the Alexander von Humboldt Foundation for his Fellowship. SJ and XG obtained financial support from the Deutsche Forschungsgemeinschaft (DFG, German Research Foundation, project nr. nr. 410768178), SAMM from USDA National Institute of Food and Agriculture Hatch project 1014908 
and RTA from CNPq-CAPES.

\section{References}

Adams HD, Zeppel MJB, Anderegg WRL, Hartmann H, Landhäusser SM, Tissue DT, Huxman TE, Hudson PJ, Franz TE, Allen CD, Anderegg LDL, Barron-Gafford GA, Beerling DJ, Breshears DD, Brodribb TJ, Bugmann H, Cobb RC, Collins AD, Dickman LT, Duan H, Ewers BE, Galiano L, Galvez DA, Garcia-Forner N, Gaylord ML, Germino MJ, Gessler A, Hacke UG, Hakamada R, Hector A, Jenkins MW, Kane JM, Kolb TE, Law DJ, Lewis JD, Limousin JM, Love DM, Macalady AK, Martínez-Vilalta J, Mencuccini M, Mitchell PJ, Muss JD, O'Brien MJ, O'Grady AP, Pangle RE, Pinkard EA, Piper FI, Plaut JA, Pockman WT, Quirk J, Reinhardt K, Ripullone F, Ryan MG, Sala A, Sevanto S, Sperry JS, Vargas R, Vennetier M, Way DA, Xu C, Yepez EA, McDowell NG (2017) A multi-species synthesis of physiological mechanisms in drought-induced tree mortality. Nature Ecology and Evolution 1: 1285-1291.

Avila RT, Cardoso AA, Batz TA, Kane CN, DaMatta FM, McAdam SAM (2021) Limited plasticity in embolism resistance in response to light in leaves and stems in species with considerable vulnerability segmentation. Physiologia Plantarum 172: 2142-2152.

Blackman CJ, Brodribb TJ, Jordan GJ (2010) Leaf hydraulic vulnerability is related to conduit dimensions and drought resistance across a diverse range of woody angiosperms. New Phytologist 188: 1113-1123.

Bouche PS, Larter M, Domec J-C, Burlett R, Gasson P, Jansen S, Delzon S (2014) A broad survey of hydraulic and mechanical safety in the xylem of conifers. Journal of Experimental Botany 65: 4419-4431.

Bouda M, Windt CW, McElrone AJ, Brodersen CR (2019) In vivo pressure gradient heterogeneity increases flow contribution of small diameter vessels in grapevine. Nature Communications 10: 5645.

Brodersen CR, McElrone AJ, Choat B, Lee EF, Shackel KA, Matthews MA (2013) In Vivo Visualizations of Drought-Induced Embolism Spread in Vitis vinifera . Plant Physiology 161: 1820-1829.

Brodribb TJ, Bienaimé D, Marmottant P (2016a) Revealing catastrophic failure of leaf networks under stress. Proceedings of the National Academy of Sciences of the United States of America 113: 865-4869.

Brodribb TJ, Carriquí M, Delzon S, McAdam SAM, Holbrook NM (2020a) Advanced vascular function discovered in a widespread moss. Nature Plants 6: 273-279.

Brodribb TJ, Cochard H (2009) Hydraulic failure defines the recovery and point of death in water-stressed conifers. Plant Physiology 149: 575-584.

Brodribb TJ, Powers J, Cochard H, Choat B (2020b) Hanging by a thread? Forests and drought. Science 368: 261-266.

Brodribb TJ, Skelton RP, McAdam SAM, Bienaimé D, Lucani CJ, Marmottant P (2016b) Visual quantification of embolism reveals leaf vulnerability to hydraulic failure. New Phytologist 209: 1403-1409.

Cardoso AA, Batz TA, McAdam SAM (2020a) Xylem Embolism Resistance Determines Leaf Mortality during Drought in $<$ em $>$ Persea americana $</$ em $>$. Plant Physiology 182: 547-554.

Cardoso AA, Visel D, Kane CN, Batz TA, García Sánchez C, Kaack L, Lamarque LJ, Wagner Y, King A, Torres-Ruiz JM, Corso D, Burlett R, Badel E, Cochard H, Delzon S, Jansen S, McAdam SAM (2020b) Drought-induced lacuna formation in the stem causes hydraulic conductance to decline before xylem embolism in Selaginella. New Phytologist 227: 1804-1817.

Choat B, Badel E, Burlett R, Delzon S, Cochard H, Jansen S (2015a) Non-invasive measurement of vulnerability to drought induced embolism by X-ray microtomography. Plant Physiol.

Choat B, Brodersen CR, McElrone AJ (2015b) Synchrotron X-ray microtomography of xylem embolism in Sequoia sempervirenssaplings during cycles of drought and recovery. New Phytologist 205: 1095-1105. 
Choat B, Brodribb TJ, Brodersen CR, Duursma RA, López R, Medlyn BE (2018) Triggers of tree mortality under drought. Nature 558: 531-539.

Choat B, Cobb AR, Jansen S (2008) Structure and function of bordered pits: new discoveries and impacts on whole-plant hydraulic function. New Phytologist 177: 608-626.

Choat B, Drayton WM, Brodersen CR, Matthews MA, Shackel KA, Wada H, McElrone AJ (2010) Measurement of vulnerability to water stress-induced cavitation in grapevine: a comparison of four techniques applied to a long-vesseled species. Plant Cell and Environment 33: 1502-1512.

Choat B, Jansen S, Brodribb TJ, Cochard H, Delzon S, Bhaskar R, Bucci SJ, Feild TS, Gleason SM, Hacke UG, Jacobsen AL, Lens F, Maherali H, Martinez-Vilalta J, Mayr S, Mencuccini M, Mitchell PJ, Nardini A, Pittermann J, Pratt RB, Sperry JS, Westoby M, Wright IJ, Zanne AE (2012) Global convergence in the vulnerability of forests to drought. Nature 491: 752-755.

Cochard H, Badel E, Herbette S, Delzon S, Choat B, Jansen S (2013) Methods for measuring plant vulnerability to cavitation: a critical review. Journal of Experimental Botany 64: 4779-4791.

Cuneo IF, Knipfer T, Brodersen CR, McElrone AJ (2016) Mechanical Failure of Fine Root Cortical Cells Initiates Plant Hydraulic Decline during Drought. Plant Physiology 172: 1669-1678.

Dalla-Salda G, Fernandez ME, Sergent A-S, Rozenberg P, Badel E, Martinez-Meier A (2014) Dynamics of cavitation in a Douglas-fir tree-ring: transition-wood, the lord of the ring? Journal of Plant Hydraulics 1: e005.

Dixon HH, Joly J (1895) On the ascent of sap. Philosophical Transactions of the Royal Society B: Biological Sciences 186: 563-576.

Gauthey A, Peters JMR, Carins-Murphy MR, Rodriguez-Dominguez CM, Li X, Delzon S, King A, Lopez R, Medlyn BE, Tissue DT, Brodribb TJ, Choat B (2020) Visual and hydraulic techniques produce similar estimates of cavitation resistance in woody species. New Phytologist 228: 884-897.

Guan X, Pereira L, McAdam SAM, Cao KF, Jansen S (2021) No gas source, no problem: proximity to pre-existing embolism and segmentation affect embolism spreading in angiosperm xylem by gas diffusion. Plant, Cell and Environment 44: 1329-1345.

Hacke UG, Sperry JS, Pittermann J (2004) Analysis of circular bordered pit function II. Gymnosperm tracheids with torus-margo pit membranes. American Journal of Botany 91: 386-400.

Hacke UG, Sperry JS, Pockman WT, Davis SD, McCulloh KA (2001) Trends in wood density and structure are linked to prevention of xylem implosion by negative pressure. Oecologia 126: 457-461.

Hacke UG, Venturas MD, MacKinnon ED, Jacobsen AL, Sperry JS, Pratt RB (2015) The standard centrifuge method accurately measures vulnerability curves of long-vesselled olive stems. New Phytologist 205: 116-127.

Jacobsen AL, Pratt RB, Venturas MD, Hacke UG (2019) Large volume vessels are vulnerable to water-stressinduced embolism in stems of poplar. IAWA Journal 40: 4-22.

Johnson KM, Brodersen CR, Carins-Murphy MR, Choat B, Brodribb TJ (2020) Xylem embolism spreads by single-conduit events in three dry forest angiosperm stems. Plant Physiology 184: 212-222.

Kaack L, Altaner CM, Carmesin C, Diaz A, Holler M, Kranz K, Neusser G, Odstrcil M, Schenk HJ, Schmidt V, Weber M, Zhang Y, Jansen S (2019) Function and three dimensional structure of intervessel pit membranes in angiosperm xylem: a review. IAWA Journal 40: 673-702.

Kaack L, Weber M, Isasa E, Karimi Z, Li S, Pereira L, Trabi C, Zhang Y, Schenk HJ, Schuldt B, Schmidt V, Jansen S (2021) Pore constrictions in intervessel pit membranes provide a mechanistic explanation for xylem embolism resistance in angiosperms. New Phytologist 230: 1829-1843. 
Knipfer T, Brodersen CR, Zedan A, Kluepfel DA, McElrone AJ (2015) Patterns of drought-induced embolism formation and spread in living walnut saplings visualized using X-ray microtomography. Tree Physiology 35: 744-755.

Lamarque LJ, Corso D, Torres-Ruiz JM, Badel E, Brodribb TJ, Burlett R, Charrier G, Choat B, Cochard H, Gambetta GA, Jansen S, King A, Lenoir N, Martin-StPaul N, Steppe K, Van den Bulcke J, Zhang Y, Delzon S (2018) An inconvenient truth about xylem resistance to embolism in the model species for refilling Laurus nobilis L. Annals of Forest Science 75: 88.

Li S, Lens F, Espino S, Karimi Z, Klepsch M, Schenk HJ, Schmitt M, Schuldt B, Jansen S (2016) Intervessel pit membrane thickness as a key determinant of embolism resistance in angiosperm xylem. IAWA Journal 37: 152-171.

Liese W, Bauch J (1967) On the closure of bordered pits in conifers. Wood Science and Technology 1: 1-13.

Martin-StPaul NK, Longepierre D, Huc R, Delzon S, Burlett R, Joffre R, Rambal S, Cochard H (2014) How reliable are methods to assess xylem vulnerability to cavitation? The issue of 'open vessel' artifact in oaks. Tree Physiology 34: 894-905.

Olson ME, Rosell JA (2013) Vessel diameter-stem diameter scaling across woody angiosperms and the ecological causes of xylem vessel diameter variation. New Phytologist 197: 1204-1213.

Pereira L, Bittencourt PRL, Rowland L, Brum M, Miranda MT, Pacheco VS, Oliveira RS, Machado EC, Jansen S, R.V. R (2021) Using the pneumatic method to estimate embolism resistance in species with long vessels: a commentary on the article "A comparison of five methods to assess embolism resistance in trees. Forest Ecology and Management 479: 118547.

Pittermann J, Sperry JS, Hacke UG, Wheeler JK, Sikkema EH (2005) Torus-margo pits help conifers compete with angiosperms. Science 310: 1924.

Schenk HJ, Espino S, Goedhart CM, Nordenstahl M, Cabrera HIM, Jones CS (2008) Hydraulic integration and shrub growth form linked across continental aridity gradients. Proceedings of the National Academy of Sciences of the United States of America 105: 11248-11253.

Schenk HJ, Michaud JM, Mocko K, Espino S, Melendres T, Roth MR, Welti R, Kaack L, Jansen S (2021) Lipids in xylem sap of woody plants across the angiosperm phylogeny. The Plant Journal 105: 1477-1494.

Schumann K, Leuschner C, Schuldt B (2019) Xylem hydraulic safety and efficiency in relation to leaf and wood traits in three temperateAcer species differing in habitat preferences. Trees 33: 1475-1490.

Scoffoni C, Albuquerque C, Brodersen CR, Townes SV, John GP, Bartlett MK, Buckley TN, McElrone AJ, Sack L (2017a) Outside-Xylem Vulnerability, Not Xylem Embolism, Controls Leaf Hydraulic Decline during Dehydration. Plant Physiology 173: 1197-1210.

Scoffoni C, Albuquerque C, Brodersen CR, Townes SV, John GP, Cochard H, Buckley TN, McElrone AJ, Sack L (2017b) Leaf vein xylem conduit diameter influences susceptibility to embolism and hydraulic decline. New Phytologist 213: 1076-1092.

Sergent AS, Varela SA, Barigah TS, Badel E, Cochard H, Dalla-Salda G, Delzon S, Fernandez ME, Guillemot J, Gyenge J, Lamarque LJ, Martinez-Meier A, Rozenberg P, Torres-Ruiz JM, Martin-StPaul NK (2020) A comparison of five methods to assess embolism resistance in trees. Forest Ecology and Management 468: 118175.

Skelton RP, Brodribb TJ, Choat B (2017) Casting light on xylem vulnerability in an herbaceous species reveals a lack of segmentation. New Phytologist 214: 561-569.

Sorek Y, Greenstein S, Netzer Y, Shtein I, Jansen S, Hochberg U (2021) An increase in xylem embolism resistance of grapevine leaves during the growing season is coordinated with stomatal regulation, turgor loss point and intervessel pit membranes. New Phytologist 229: 1955-1969. 
Torres-Ruiz JM, Cochard H, Mencuccini M, Delzon S, Badel E (2016) Direct observation and modelling of embolism spread between xylem conduits: a case study in Scots pine. Plant, Cell and Environment 39: 2774-2785.

Trifilo P, Raimondo F, Lo Gullo MA, Barbera PM, Salleo S, Nardini A (2014) Relax and refill: xylem rehydration prior to hydraulic measurements favours embolism repair in stems and generates artificially low PLC values. Plant, Cell and Environment 37: 2491-2499.

Tyree MT, Sperry JS (1989) Vulnerability of xylem to cavitation and emoblism. Annual Review of Plant Physiology and Plant Molecular Biololgy 40: 19-36.

Urli M, Porte AJ, Cochard H, Guengant Y, Burlett R, Delzon S (2013) Xylem embolism threshold for catastrophic hydraulic failure in angiosperm trees. Tree Physiology 33: 672-683.

Venturas MD, Rodriguez-Zaccaro FD, Percolla MI, Crous CJ, Jacobsen AL, Pratt RB (2016) Single vessel air injection estimates of xylem resistance to cavitation are affected by vessel network characteristics and sample length. Tree Physiology 36: 1247-1259.

Wang Y, Pan R, Tyree MT (2015) Studies on the tempo of bubble formation in recently cavitated vessels: a model to predict the pressure of air bubbles. Plant Physiology 168: 521-531.

Wason J, Bouda M, Lee EF, McElrone AJ, Phillips RJ, Shackel KA, Matthews MA, Brodersen C (2021) Xylem network connectivity and embolism spread in grapevine (Vitis vinifera L.) Plant Physiology !86: 373-387.

Yang J, Michaud J, Jansen S, Schenk HJ, Zuo Y (2020) Dynamic surface tension of xylem sap lipids. Tree Physiology 40: 433-444.

Zhang Y, Carmesin C, Kaack L, Klepsch MM, Kotowska M, Matei T, Schenk HJ, Weber M, Walther P, Schmidt V, Jansen S (2020) High porosity with tiny pore constrictions and unbending pathways characterize the 3D structure of intervessel pit membranes in angiosperm xylem. Plant, Cell and Environment 43: 116130 . 

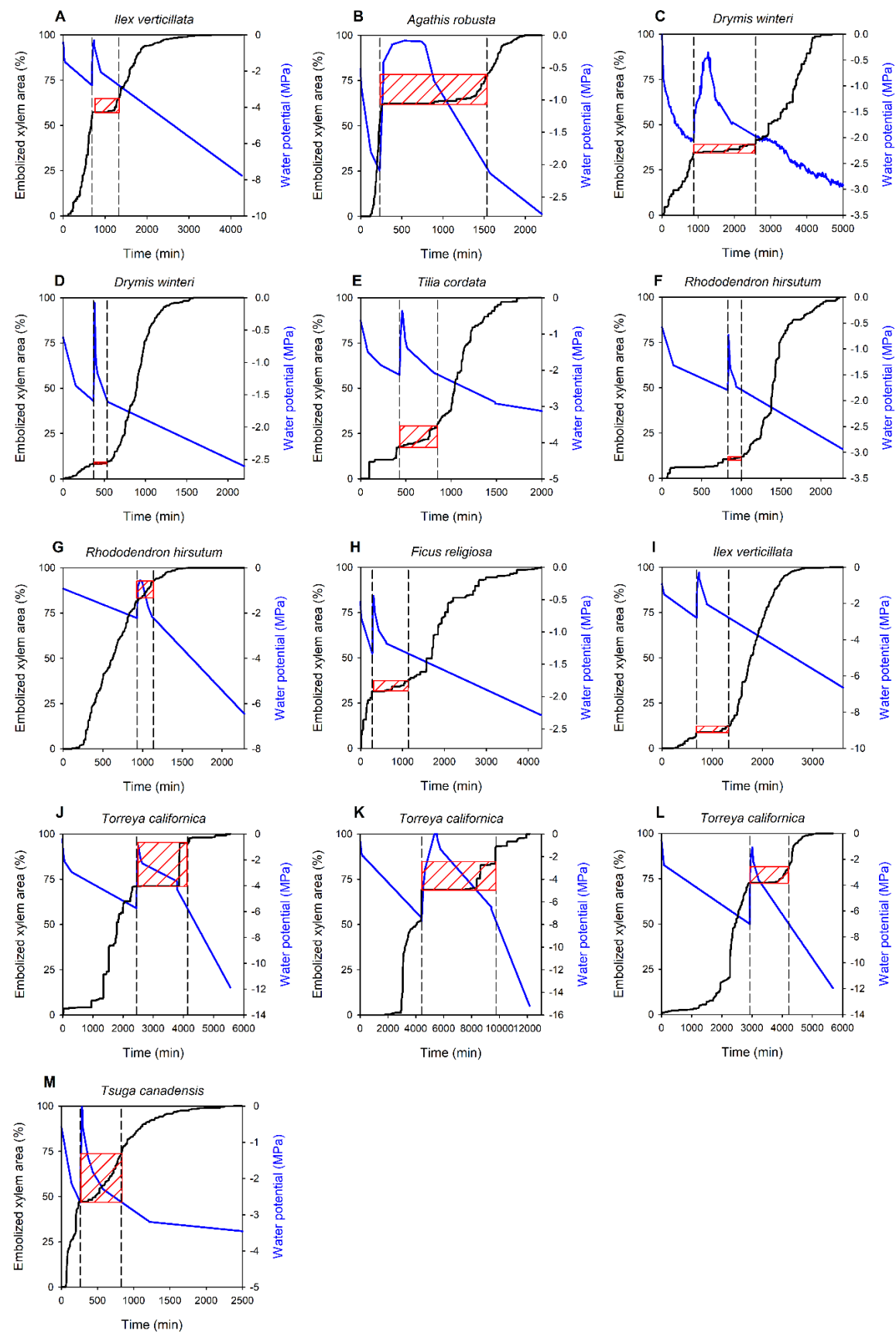

Supplementary Figure S1. Accumulation of embolism (black) and water potential (blue) through time in stems of Ilex verticillata(A), Agathis robusta (B), Drymis winteri (C and D), Tilia cordata (E), Rhododendron hirstum ( $\mathrm{F}$ and $\mathrm{H})$,Ficus religiosa $(\mathrm{I})$, I. verticillata $(\mathrm{J})$, Torreya californica $(\mathrm{K}-\mathrm{M})$ and Tsuga canadensis $(\mathrm{N})$. The first vertical dashed line indicates when plants were rehydrated, and the second vertical dashed line indicates the time when plants reached a similar water potential to when rehydration occurred. The red box represents the amount of embolism that occurred in the period between rehydration and when water potential had declined to the value it was when rehydration occurred. 

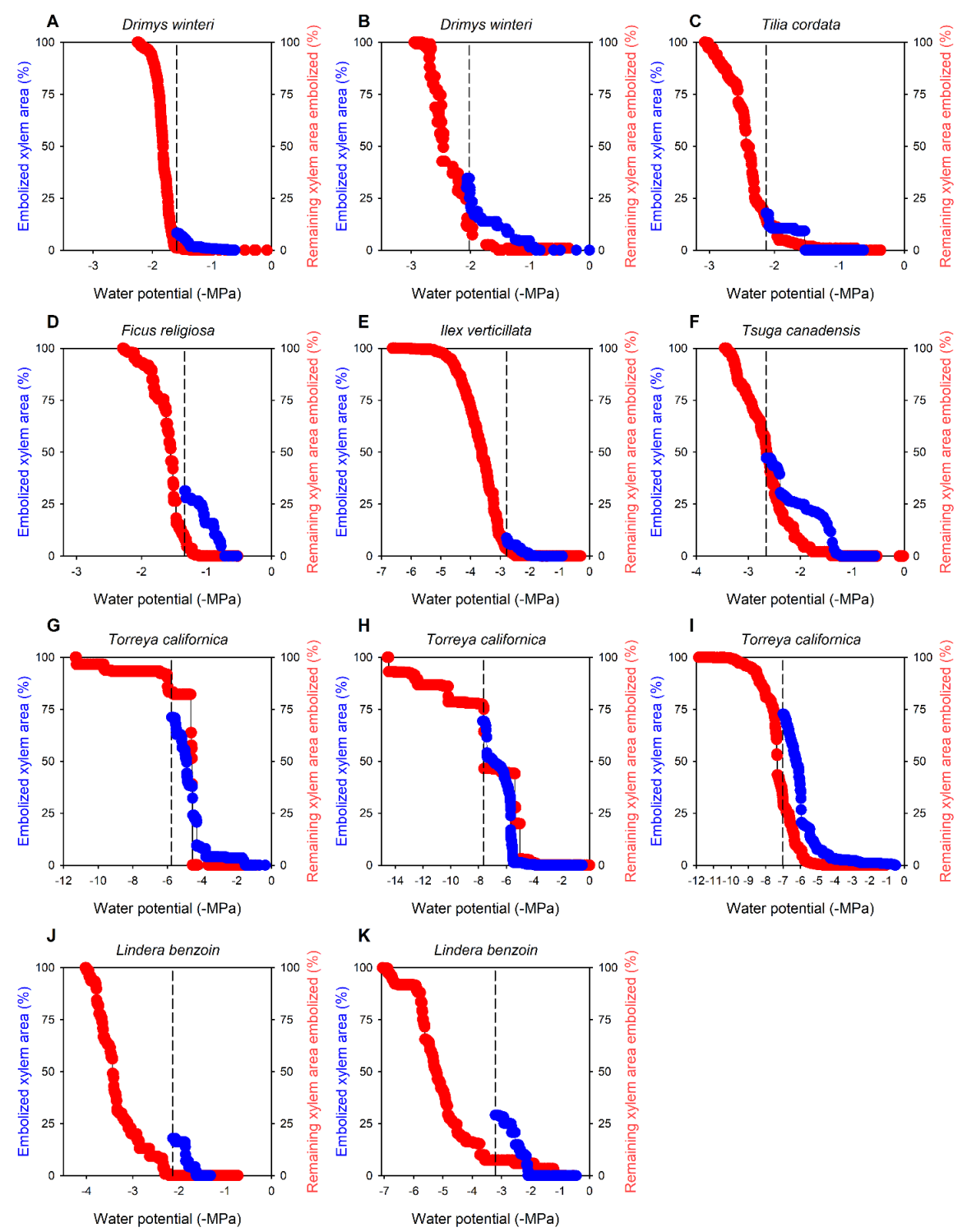

Supplementary Figure S2. Cumulative embolized xylem area as a percentage of total embolized area on the first cycle of dehydration (blue) in stems of Drymis winteri (A and B), Tilia cordata $(\mathrm{C})$, Ficus religiosa (I), I. verticillata (E), Tsuga canadensis (F), Torreya californica (G-I) and leaves ofLindera benzoin (J and $\mathrm{K})$. The water potential at rehydration is marked by a vertical dashed line. Cumulative embolized xylem area as a percentage of the remaining un-embolized xylem area on the second cycle of dehydration (red) for each species is also shown. 